ORIGINAL ARTICLE

\title{
Delphi based consensus study into planning for chemical incidents
}

\author{
I W F Crawford, K Mackway-Jones, D R Russell, S D Carley
}

Emerg Med J 2004;21:24-28

See end of article for authors' affiliations

.....................

Correspondence to:

Dr I W F Crawford

Department of Emergency

Medicine, Manchester

Royal Infirmary, Oxford

Road, Manchester M13

9WL, UK; ian.crawford@

cmmc.nhs.uk

Accepted for publication

2 February 2003

\begin{abstract}
Objective: To achieve consensus in all phases of chemical incident planning and response. Design: A three round Delphi study was conducted using a panel of 39 experts from specialties involved in the management of chemical incidents. Areas that did not reach consensus in the Delphi study were presented as synopsis statements for discussion in four syndicate groups at a conference hosted by the Department of Health Emergency Planning Co-ordination Unit.

Results: A total of 183 of 322 statements had reached consensus upon completion of the Delphi study. This represented $56.8 \%$ of the total number of statements. Of these, 148 reached consensus at $>94 \%$ and 35 reached consensus at $>89 \%$. The results of the process are presented as a series of synopsis consensus statements that cover all phases of chemical incident planning and response.

Conclusions: The use of a Delphi study and subsequent syndicate group discussions achieved consensus in aspects of all phases of chemical incident planning and response that can be translated into practical guidance for use at regional prehospital and hospital level. Additionally, areas of non-consensus have been identified where further work is required.
\end{abstract}

A cute exposure to chemical substances may occur in many ways, for example at industrial sites that handle, store or manufacture chemicals, during transportation of chemicals by road, rail, sea or air, or as a result of a deliberate release by a terrorist organisation. The National Focus for Chemical Incidents surveillance data show that there are about 1300 chemical incidents annually in the United Kingdom, most involving less than 10 chemically contaminated casualties. ${ }^{1}$ This contrasts with major incidents, which occur at a rate of four to five each year in the United Kingdom. ${ }^{2}$ Chemical incidents are, therefore, comparatively common. However, there are currently deficiencies in the health service capability to respond to such incidents. ${ }^{3}{ }^{4}$

When planning for chemical incidents, whether the consequence of accidental or deliberate release, the health service must ensure that appropriate health care measures are being provided by emergency departments, ambulance services, and other providers to both guard the health, safety, and welfare of their own employees and also assist and treat potentially large numbers of chemically contaminated casualties. ${ }^{5}$

To fulfil this duty of care, there is the requirement for the provision of appropriate equipment and facilities, and a need for training and specific chemical incident plans for emergency departments and ambulance services.

As part of a wider project to consider these issues, the Department of Health Emergency Planning Co-ordination Unit commissioned this study, the aims of which were to achieve consensus in all phases of chemical incident planning and response.

\section{METHODS}

A three round Delphi study ${ }^{6}$ (appendix) was conducted between October 2000 and February 2001 using a panel of 39 experts, identified by the authors and the Department of Health Emergency Planning Co-ordination Unit project steering group, from specialties involved in the management of chemical incidents.

Expertise was ascribed using two criteria. Firstly, evidence of experience in chemical incidents; secondly, if people held positions of authority and influence within the sphere of emergency planning. ${ }^{7}$ This was to ensure that decisions were made by persons in senior posts, so that subsequent recommendations and their implementation would be eased. ${ }^{7}$ A list of the members of the Delphi panel can be found at the end of this paper. Forty one people were approached, of whom 39 agreed to participate. Thirty one participants $(79.5 \%)$ completed round 1; all 39 participants (100\%) completed rounds 2 and 3.

Round 1 of the Delphi study asked participants to consider chemical incidents broadly in the areas of preparation, onscene response, hospital response, specialist unit response, and post-incident care and follow up. Their replies were collated into a series of statements.

Round 2 comprised 298 statements. Panel members were required to express their level of agreement with each statement using a Likert scale. ${ }^{8}$ Panel members were also asked to add any comments that they felt were appropriate and to mention any areas that they felt were important and which had not already been mentioned.

The third and final round of the Delphi study presented those statements that had not reached consensus at the end of round two, together with a summary of the rest of the panel's findings (fig 1). In this round panel members could change their opinions in light of those of the rest of the group.

Consensus was defined a priori to be $>94 \%$ at the end of round 2 and $>89 \%$ at the end of round 3 -that is, 37 and 35 members respectively of the panel who had scored an individual statement scoring it as 6 or above. Statements that reached consensus at the end of round 2 were not reiterated in round 3.

Twenty four additional statements, including 18 statements on risk assessment, were constructed and added in round 3. These were prompted by panel members identifying new areas of concern in round 2.

Data were collated and analysed using SPSS version 9.0 to calculate frequencies, mean, and range of scores.

Areas that had not reached consensus in the Delphi study were presented as synopsis statements for discussion in four 


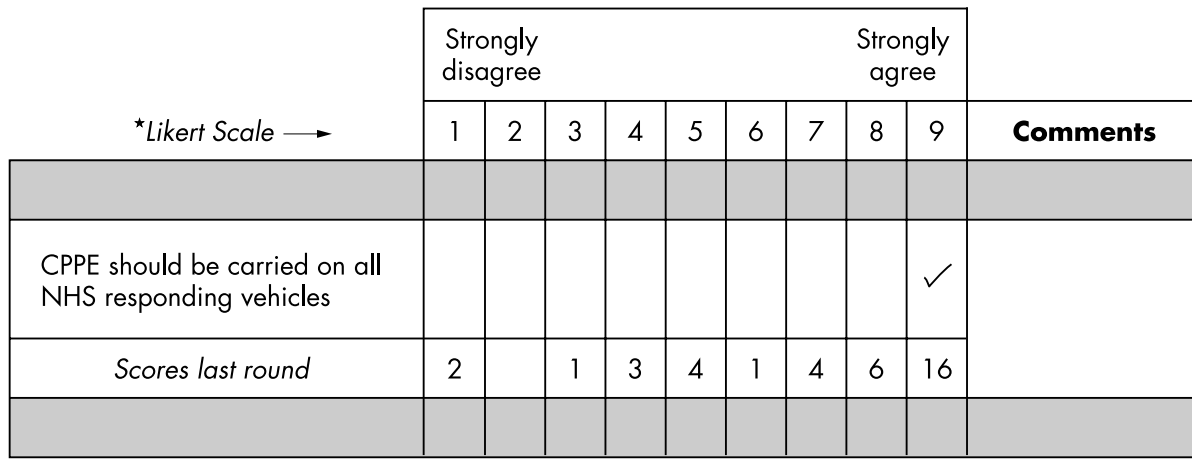

Figure 1 Example of Delphi statment in round 3. * The Likert Scale allows a subjective view - that is, a level of agreement-to be converted into a numerical value and analysed statistically. syndicate groups at a one day consensus conference hosted by the Department of Health Emergency Planning Coordination Unit on 26 February 2001. All those originally approached to participate in the Delphi study were invited to attend, along with other stakeholders as identified by the Department of Health Emergency Planning Co-ordination Unit. Each group discussion was led by a facilitator from the Department of Health Emergency Planning Co-ordination Unit project steering group. Results of each syndicate group discussion were presented at a subsequent plenary session at the end of the conference.

\section{RESULTS}

A total of 183 of 322 statements had reached consensus upon completion of rounds 2 and 3. This represents $56.8 \%$ of the total number of statements. Of these, 148 reached consensus at $>94 \%$ and 35 reached consensus at $>89 \%$. The results are presented as synopsis statements of the main points of consensus from rounds 2 and 3 . The full set of statements can be found on the journal web site (http://www.emjonline.com/ supplemental). Additionally, those areas of non-consensus reaching agreement at the one day consensus conference are also presented as synopsis statements. These statements are clearly indicated by an asterisk.

These results are shown under the areas of preparation, prehospital response, hospital response, and post-incident recovery and support.

\section{SYNOPSIS OF CONSENSUS STATEMENTS ON PREPARATION Planning}

(1) A chemical incident involves the release of substances that necessitates special arrangements to protect staff, the environment, and the patient.

(2) *Chapter 8 of the current NHS guidances does not provide sufficient detail for planning for chemical incidents, particularly in relation to chemical personal protective equipment (CPPE) and decontamination.

(3) Specific planning for chemical incidents is required at all levels of the health service.

(4) Chemical incident plans should dovetail with existing major incident plans and may need to be initiated even if there is only one casualty.

(5) Those involved in planning for chemical incidents should include personnel with responsibility for emergency planning, emergency services, senior emergency department medical and nursing staff, BASICs doctors, specialist units (for example, National Poisons Information Service, Chemical Incident Provider Units, the National Focus for Chemical Incidents), public health, occupational health, the environment agency, the water authority, and the military.
(6) *When planning for chemical incidents consultation with any additional groups who might be involved in the response to a chemical incident, for example, intensivists, physicians, surgeons, should occur.

(7) Plans should detail the different roles of the specialist units and these should have a central point of contact for the ambulance service and emergency departments to reduce confusion and to make accessing relevant information easier.

(8) There should be coordination of the specialist unit response in the event of an incident that has the potential to involve more than one unit.

(9) *Chemical incident plans should not detail treatment regimens.

(10) *All emergency departments should be capable of handling chemically contaminated casualties. There should not be designated receiving hospitals for chemically contaminated casualties allocated on a subregional basis.

(11) An annually reviewed local risk assessment should be undertaken, in association with all agencies, to determine the adequacy of existing health service arrangements in light of perceived acceptable risk and with a strategy in place to reduce risk if required.

(12) Factors that should be considered when undertaking a local risk assessment are geography, population density, transport arrangements for hazardous substances, use and storage of chemicals by all industrial establishments and the availability of CPPE and decontamination facilities by all agencies (including industry).

\section{Equipment}

(13) All emergency departments and ambulance services should have a specified minimum amount of CPPE and decontamination facilities and should provide action cards for their use.

(14) * CPPE should be carried on responding vehicles.

(15) *Ambulance services should have a dedicated response (similar to HAZMAT) for use in chemical incidents. Numbers required per ambulance service should be dependent upon local risk assessment.

(16) There should be an evidence based, generic specification for CPPE to be used by all health service personnel, which should protect against skin contact, eye contact and inhalation, and take into account usability.

(17) There should be an evidence based specification for decontamination facilities.

(18) Decontamination facilities should be available for use on-scene.

(19) Decontamination facilities should be sited so as to minimise the risk of contaminating other areas, be ventilated, have a safe electrical source, have a warm water 
supply, be capable of taking stretcher patients and be easily cleaned.

(20) At hospital, the entrance to the decontamination facility should be separate to that of the emergency department, with an exit into the emergency department. Provision should be made for the safe disposal of contaminated clothing and materials.

(21) The methodology for the decontamination process should be evidence based.

\section{Training}

(22) There should be a national training standard for chemical incidents that should be delivered at local level to all emergency department medical and nursing staff and ambulance service personnel.

(23) *There should be national training and accreditation for trainers who would then deliver training at local level.

(24) Training should include the definition of a chemical incident, triage, the correct use of CPPE and decontamination equipment, patient and staff decontamination, and recognition of patterns of illness relating to groups of chemicals.

(25) *Training in the use of CPPE and decontamination facilities should occur at least twice yearly and as frequently as required to take into account staff changes.

(26) Chemical incident exercises involving mock chemically contaminated casualties are an appropriate test of the effectiveness of a training programme. Exercises should also test effectiveness of communication links with specialist units.

(27) * Major incident exercises should include mock chemically contaminated casualties dependent upon local exercise objectives and training needs.

(28) Tabletop exercises with all agencies should occur annually.

(29) Specific training should be developed in association with local industrial sites, based upon local risk assessment.

\section{SYNOPSIS OF CONSENSUS STATEMENTS ON PREHOSPITAL RESPONSE \\ Assessment}

(1) When assessing the scene the characteristics of chemicals involved that should be considered are toxicity, latency, and persistency. In addition, the route of exposure is important in determining the potential of harm to health.

\section{Command}

(2) Command structure and responsibilities should follow the same approach as for a major incident-that is, principles of gold, silver, and bronze command apply, with the ambulance command, and medical command, if present, in command of the health service response on-scene.

(3) * Only fire service personnel should work within the hot zone. Exceptionally, at the request of the fire service HAZMAT officer, where circumstances dictate that advice or assistance in casualty management is required, health service personnel may be required to enter the hot zone. This should only occur under fire service supervision and providing appropriate CPPE is available.

\section{Safety}

(4) Responsibility for safety on-scene should be coordinated between the fire service HAZMAT officer and the ambulance safety officer.
(5) Once a chemical incident has been declared all noncontaminated, non-protected personnel should be evacuated from the area.

(6) The incident scene should have limited access and be identified by a clear cordon, taking into account the type of chemical involved, wind direction, and the proximity of local watercourses.

(7) Rescue of chemically contaminated casualties from the hot zone is the responsibility of the fire service.

(8) *Decontamination of health service staff and vehicles is the responsibility of the ambulance service, with decontamination of vehicles occurring on-scene so as to link with existing waste management arrangements.

(9) *Decontamination of health service personnel should proceed by using the "buddy" system followed by the removal of decontaminated $\mathrm{CPPE}$, subject to adequate training and quality control.

\section{Communication}

(10) *Communication arrangements should follow nationally agreed standards for communication in major incidents.

(11) Once a chemical incident has been declared communication links should be established between health service staff on-scene and the receiving hospital(s). Notification will permit the implementation of hospital plans for ambulance and self referring casualties.

(12) Additional communication links should be available with specialist units, for example, National Poisons Information Service, Chemical Incident Provider Units, if required.

(13) *Liaison with specialist units on-scene should be the joint responsibility of the ambulance command and medical command, if present.

\section{Triage}

(14) *The fire service should not undertake the triage sieve in the hot zone.

(15) Triage of chemically contaminated casualties should be carried out by trained personnel wearing appropriate CPPE and should be *modified to take into account the difficulties when wearing CPPE.

(16) *The triage sieve is adequate to prioritise chemically contaminated casualties for decontamination.

(17) *Triage should not divide casualties into contaminated/ exposed. All casualties should undergo decontamination prior to leaving the scene.

\section{Treatment}

(18) *Decontamination of chemically contaminated casualties on-scene is the responsibility of the ambulance service.

(19) *Health service personnel should wear appropriate CPPE to carry out decontamination and/or medical treatment onscene.

(20) Decontamination should be viewed as part of the initial treatment, not an additional process, and should occur within the warm zone, before transport, to avoid or reduce contamination to ambulances and onwards to receiving hospitals.

(21) *Decontamination of chemically contaminated casualties should occur before treatment of illness/injury, with the exception of basic life support to include simple airway manoeuvres and control of external haemorrhage. 
(22) *Before the arrival of on-scene decontamination facilities, and providing appropriate CPPE is available, decontamination should start using basic decontamination equipment (bucket, sponge, water, paper towels).

(23) All items of clothing should be removed before decontamination, unless medically contraindicated, and the facial area decontaminated before the application of any ventilation equipment.

(24) *The "rinse-wipe-rinse" approach to decontamination should be used.

(25) *Special consideration should be given to eye decontamination.

(26) Specific antidotes should be administered where appropriate and when available.

\section{Transport}

(27) Transportation requirements will be dependent upon the numbers of casualties.

(28) Once decontaminated, priority for transport should be determined as for non-chemical incidents. Chemically contaminated casualties should only be transported to hospitals that have appropriate CPPE and decontamination facilities.

(29) *Exceptionally, the ambulance service should be prepared to transport chemically contaminated casualties.

(30) *Vehicles should be re-used at an incident. The use of helicopters is not acceptable as a mode of transport.

\section{SYNOPSIS OF CONSENSUS STATEMENTS ON HOSPITAL RESPONSE Triage}

(1) *It should be assumed that all casualties from a chemical incident arriving at hospital are chemically contaminated, with the exception of those who have already been decontaminated on-scene by a recognised decontamination process.

(2) *On arrival at hospital (potentially) chemically contaminated casualties should be triaged by trained emergency department clinical staff using a separate triage algorithm to allocate priority for decontamination and treatment.

(3) Emergency departments should have a designated area capable of being used as a separate holding/waiting area for (potentially) chemically contaminated casualties.

\section{Treatment}

(4) *Health service staff should wear appropriate CPPE to carry out decontamination. Thereafter it should be recommended that staff protect themselves with the normal "universal" precautions (gloves, apron, eye protection, etc).

(5) Decontamination on arrival at hospital is not required if this has already been carried out on-scene by a recognised decontamination process.

(6) On arrival at hospital decontamination of chemically contaminated casualties should occur as quickly as possible with prior removal of all items of clothing, unless medically contraindicated.

(7) During the decontamination process simple airway manoeuvres, supplemental oxygen and control of external haemorrhage should be available. *Analgesia, CPR, and full resuscitation room facilities should not be available during the decontamination process.

(8) *Decontamination methodology should be the same at hospital as on-scene.
(9) *After decontamination medical treatment should be symptomatic/supportive and should follow specific treatment recommendations when appropriate.

(10) Treatments that should be available include adrenaline, atropine, benzodiazepines, inotropes, oximes, and other specific antidotes. Availability of combo pens is not required. (11) Initial baseline investigations should be carried out on all chemically contaminated casualties.

(12) Emergency departments should have access to specialist advice at all times and to assistance from all hospital specialties if required.

(13) *Assistance should also be available from public health and the chemical industry if required. Pending further information on its remit, the National Chemical Emergency Service may also be able to provide assistance

\section{Transfers}

(14) *Chemically contaminated casualties should only be referred to tertiary centres after decontamination.

(15) Intrahospital or interhospital transfers should depend upon resources and requirements (for example, ICU spaces, availability of appropriate specialist expertise) and should not occur until after the patient has been decontaminated.

\section{SYNOPSIS OF CONSENSUS STATEMENTS ON POST- INCIDENT RECOVERY AND SUPPORT}

(1) There should be debriefing of all agencies as soon as possible after a chemical incident so those lessons learnt can be incorporated into future planning.

(2) There should be "flagging" of patients' medical records to facilitate long term epidemiological follow up.

(3) There should be post-incident surveillance of all involved patients for potential delayed onset of symptoms.

(4) Occupational exposure monitoring, to be carried out by occupational health, should be undertaken if there is evidence of damage to CPPE, penetration and/or permeation of contaminant through CPPE, if there are clinical signs of exposure and dependent upon the chemical involved.

(5) *Occupational exposure monitoring should be available to all staff, but the option to undertake this should be personal choice.

(6) *Occupational health should take the lead in identifying/ arranging appropriate sources of occupational exposure monitoring, for example, through general practitioners.

\section{DISCUSSION}

Conducting research into chemical incidents is difficult because the events are unpredictable. As clinical experimentation is impossible, practice has traditionally been based upon case reports and the opinions of experts. The opinions of single authorities are susceptible to bias, as are committees and expert working groups through confounding by interpersonal relationships. The Delphi method was used as a multidisciplinary approach in an attempt to reduce bias. ${ }^{9}$

The Delphi study produced a series of statements, covering all aspects of planning and response, on which the panel of experts achieved consensus. However, the findings should be interpreted with some caution for the following reasons.

Firstly, the definition of expertise is a subjective one, which relies upon the lead researcher and advisors knowing who are the potential experts in the field. Representation was sought from all specialties with an interest in chemical incidents, based upon our own knowledge and that of the Department of Health Emergency Planning Co-ordination Unit project 
steering group. Secondly, the Delphi method only explored those areas of concern raised by panel members and therefore important areas may have been overlooked. Thirdly, although consensus was reached on $56.8 \%$ of statements this may not necessarily mean agreement as panel members may have changed their views to draw the process to a close. However, the levels of consensus, defined a priori, were much higher that those traditionally acceptable to researchers using the Delphi technique.

The Delphi study also produced a series of statements on which the panel of experts did not produce consensus at the designated level. These were a total of 139 statements $(43.2 \%)$. As decisions about these statements had to be made for practical reasons a one day consensus conference was convened to resolve these issues. Synopsis statements, based upon the 139 non-consensus statements, were used to structure syndicate group discussions. This ensured that all ideas were identified before evaluation and that ideas with little support could be eliminated without time consuming discussion. ${ }^{10}$ While we recognise the limitations of this approach, further consensus was reached on some of these issues at that time and is incorporated into the final results.

The Delphi methodology is gaining increasing popularity in health services research and has previously been used in the context of emergency planning to improve the care of children $^{11}{ }^{12}$ and burns victims ${ }^{13}{ }^{14}$ in major incidents.

The Delphi study and subsequent syndicate group discussions did not produce a succinct set of guidelines for use in the event of a chemical incident. An accompanying paper ${ }^{15}$ illustrates how the consensus achieved can be translated into practical guidance for use at regional prehospital and hospital level.

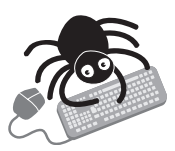

The full set of statements can be found on the journal web site (http://www.emjonline.com/supplemental).

\section{Authors' affiliations \\ I W F Crawford, K Mackway-Jones, S D Carley, Department of Emergency Medicine, Manchester Royal Infirmary, Manchester, UK D R Russell, The National Focus for Chemical Incidents, University of Wales Institute Cardiff (UWIC), Cardiff, UK}

\section{APPENDIX THE DELPHI PROCESS}

A Delphi study is a structured process that uses a panel of experts to investigate a complex or imprecise issue using a series of structured statements. It was originally designed for use by futurologists at the RAND Corporation during the 1960s. It has since been used in many other areas, most recently in the health care sciences. The process occurs in three stages:

Stage 1 A panel of experts formulates a series of ideas pertaining to the subject in question. This is done individually and anonymously.

Stage 2 The statements from stage 1 are collated and sent to all members of the panel. They indicate their level of agreement with each statement using a Likert scale.

Stage 3 Each statement is fed back to the panel with their own and the rest of the panel's previous opinions. All feedback is anonymous. Numerous iterations may be necessary.

\section{DELPHI PANEL MEMBERS}

Mr Bill Johnston Emergency Planning Manager, Tees Ambulance Service; Mr Ian Bateman Education and Training Manager, Gloucestershire Ambulance Service; Mr Alan Parker Ambulance Service Advisor, Department of Health; Mr Tony Rowe Senior Emergency Planning Advisor, London Ambulance Service; Mr Mike
Herriott National Emergency Planning Officer, Scottish Ambulance Service; Dr Andrew Marsden Medical Director, Scottish Ambulance Service; Dr Iain McNeill Medical Director, Surrey Ambulance Service; Dr Colville Laird BASICs / GP, St Margaret's Health Centre, Auchterarder; Dr Brian Robertson Chair BASICs/GP, The Surgery, Aldershot; Dr Ken Hines BASICs/GP, Eastwood Medical Centre, London; Mr Tony Bleetman Emergency Physician, Birmingham Heartlands Hospital; Mr Mark Prescott Emergency Physician, Royal Shrewsbury Hospital; Mr Derek Burke Paediatric Emergency Physician, Sheffield Children's Hospital; Mr Kyee Han Emergency Physician, Middlesborough General Hospital; Professor Tim Hodgetts Speciality Advisor, Defence Medical Services, Frimley Park Hospital; Mr John Heyworth Emergency Physician / President BAEM, Southampton General Hospital; Mr Gary Ward Emergency Physician, Coventry and Warwickshire Hospital; Mr Rupert Evans Emergency Physician, University Hospital of Wales; Sr Christine Davey Emergency Nursing, Northern General Hospital; Sr Jane Davis Emergency Nursing, West Middlesex Hospital; Mr Peter Davies Senior Manager, Chemical Incident Management Support Unit; Dr Virginia Murray Medical Director, Chemical Incident Response Service; Ms Gill Pagliuca New Products Manager, National Chemical Emergency Centre; Dr David Russell Medical Director, the National Focus for Chemical Incidents; Ms Jody Foster Regional Environmental Health Officer, PHLS South West Region; Mr Martin Hall Chief Environmental Health Officer, Isle of Man; Professor Peter Blain Professor of Environmental and Occupational Medicine, Newcastle University; Dr Kai Lau Consultant in Communicable Disease Control, Kensington and Chelsea Health Authority; Dr Giles Morgan Consultant Intensivist and President Intensive Care Society, Royal Cornwall Hospital; Dr Peter Nightingale Consultant Intensivist and President-elect Intensive Care Society, Withington Hospital; Mr Peter Davis Emergency Planner, Avon Health Authority; Mr Allan Bailey Health Emergency Planning Advisor, NHS Executive South East Region; Mr Gordon Tunley Health Emergency Planning Advisor, NHS Executive/Department of Health; Mr Mike Boocock Health Emergency Planning Advisor, NHS Executive Trent Region; Mr David Goulding Health Emergency Planning Advisor, National Assembly for Wales; Mr Chris Hickinbotham Health Emergency Planning Advisor, Scottish NHS Executive; Dr Duncan Macpherson Head Emergency Planning Co-ordination Unit, Department of Health; Lt Col D Morgan-Jones Chief Instructor, Defence Medical Services Training Centre, Aldershot; Major John Kay SOl, NBC Training School, Winterbourne Gunner.

\section{REFERENCES}

1 The National Focus for Chemical Incidents. Surveillance report (final quarter 2000 and first quarter 2001). Cardiff: The National Focus for Chemical Incidents, 2001.

2 Carley SD, Mackway-Jones K, Donnan S. Major incidents in Britain in the past 28 years: the case for the centralised reporting of major incidents. J Epidemiol Community Health 1998:52:392-8.

3 Horby $\mathbf{P}$, Murray V, Cummins A, et al. The capability of accident and emergency departments to safely decontaminate victims of chemical incidents. $J$ Accid Emerg Med 2000;17:344-7.

4 George G, Ramsay K, Rochester M, et al. Facilities for chemical decontamination in accident and emergency departments in the United Kingdom. Emerg Med J 2002;19:453-7.

5 Department of Health. Planning for major incidents: the NHS guidance. London: Department of Health, 1998.

6 Jones J, Hunter D. Consensus methods for medical and health services research. BMJ 1995;311:376-80.

7 Rauch W. The decision Delphi. Technological Forecasting and Social Change 1979;15:159-69.

8 Likert A. A technique for the measurement of attitudes. Arch Psychol (Frankf) 1932;22:55.

9 Goodman CM. The Delphi technique: a critique. J Adv Nurs 1987; 12:729-34.

10 Whitman NI. The Delphi technique as an alternative for committee meetings. J Nurs Educ 1990;29:377-9.

11 Carley SD, Mackway-Jones K, Donnan S. Delphi study into planning for care of children in major incidents. Arch Dis Child 1999;80:406-9.

12 Mackway-Jones K, Carley SD, Robson J. Planning for major incidents involving children by implementing a Delphi study. Arch Dis Child 1999:80:410-13.

13 Randic L, Carley SD, Mackway-Jones K, et al. Planning for major burns incidents in the UK using an accelerated Delphi technique. Burns 2002;28:405-12.

14 Carley SD, Mackway-Jones K, Randic L, et al. Planning for major burns incidents by implementing an accelerated Delphi technique. Burns 2002;28:413-18.

15 Crawford IWF, Mackway-Jones K, Russell DR, et al. Planning for chemical incidents by implementing a Delphi based consensus study. Emerg Med J 2004;21:20-3. 